\title{
A magia do silêncio nas Artes Visuais *
}

Silêncio é normalmente percebido como um ilusório cessar de todos os sons. Na realidade, o silêncio apenas existe dentro do contexto de uma relação, como um contraponto aos sons e ruídos, come um elemento contrastante: nossa audição está sempre apreendendo alguma coisa, ainda que apenas as batidas de nosso próprio coração.

No entanto, por mero contraste, $u$ silêii cio pode tomar a forma de uma real presença, com uma individualidade própria: quando cessam os ruídos, por exemplo, o silêncio que se evidencia nos provoca uma agradável sensação de alívio; num diálogo, uma palavra em suspenso nos evoca um sentido de expectativa; dentro de uma melodia, o silêncio ou os intervalos silenciosos são parte da música exaltando-a, pontuando-a. Portanto, o poder e a magia do silêncio ficam subordinados a seus elementos contrastantes: ao negá-los, suspendê-los ou interrompê-los, ele se torna significante em si mesmo e também modifica o significado dos elementos próximos a ele.

Nas artes visuais, dentro da articulação de formas cheias e vazias, na luz imaterial que pode formar objetos ou dissolver seus contornos, uma luz que pode revelar detalhes ou escondê-los totalmente, uma área neutra que atrai a nossa atenção justamente porque não esteja provendo nenhum significado óbvio ou convencional, nós podemos perceber inúmeras analogias com aquelas propriedades quase miraculosas do silênicio. $\mathrm{O}$ que eu descrevo aqui como propriedades quase miraculosas são precisamente as vagas sensações ou a multiplicidade de significados que o conceito de silêncio, quando inserido em diferentes contextos, pode trazer à nossa percepção.

Dentro da complexidade de uma língua discursiva, palavras separadas têm uma referência convencional fixa, mas quando arranjadas em diferentes frases,

* Excerto de um dos trabalhos da Tese escrita para a obtenção do Grau de M.F.A. em Gravura, pela Colorado State University, USA, 1985. 
elas podem evocar impressões totalmente diferentes. Este arranjo é a forma abstrata que expressa a ordem de nossas idéias e sentimentos.

Nas artes visuais, no entanto, os elementos constitutivos, tais como: linhas, configuraçðes, ritmos, cor, não possuem um significado pré-fixado ou uma referência convencional: somente quando eles são articulados em um todo estruturado onde podemos perceber uma ordem e conexões internas, poderemos ser capazes de perceber, naquela ordem, algumas similaridades com a ordem das idéias e dos sentimentos. Este relacionamento é sempre simbólico e abstrato, e como todas as relaçð̃es simbólicas entre o símbolo e o objeto simbolizado, é sempre simétrica, isto é, atua em ambas as direções.

Desejo enfatizar aqui, no entanto, que a noção de silèncio pode apenas ser apreendida, nas artes visuais, num sentido metafórico - como imobilidade e serenidade - tais como as vemos nos trabalhos de Giorgic Morandi, por exemplo: como linhas de movimentos lentos e cores atenuadas; que caracterizam algumas pinturas de William Baziotes; como opacidade e impenetrabilidade, que percebemos nas pinturas de paredes, muros e portas de Antoni Tàpies; na supressão do conteúdo literário ou "conteúdo atemporal" nas pinturas de Mark Rothko. Nestes exemplos, a característica primordial do silêncio é a imobilidade ou muito sutis movimentos lentos.

A analogia entre imobilidade e silêncio é mais fácil de ser percebida do que a analogia entre silêncio e lentidão. Em primeiro lugar, silêncio nos traz imediatamente à mente a idéia de "parada". No entanto, o silêncio também provoca a exaltação de nossa capacidade de atenção. E é aqui que a relação entre o silêncio e a lentidão pode ser percebida: um olhar atente é um olhar demorado, ou lento; sempre que estamos prestando atenção em alguma coisa, a consciência de todas as outras percepções sensoriais fica atenuada, a nível pré- consciente, mas à medida em que voltamos a fixar o nosso olhar no mesmo objeto, por um tempo mais longo, outras inferências perceptivas, advindas da memória de nossos outros sentidos, podem transformar, significativamente, a impressão daquilo que vemos.

Esse complexo mecanismo perceptivo, que se passa a nível préconsciente, silencioso, transforma a experiência visual de uma recepção passiva, retiniana, a uma recepção enriquecida, instigante. Quando prestamos atenção ao que estamos olhando, nós vemos mais e melhor; quando prestamos atenção ao que estamos escutando, nós ouvimos mais e melhor.

Existe um outro aspecto do ato de olhar que desejo mencionar aqui: um olhar combinado com concentração ou com uma exaltada capacidade de atenção é um olhar que questiona o que vê, é um "encarar" o objeto à frente de nossos olhos. É o oposto de um olhar fugaz e rápido, que toma por já visto aquilo que acaba de olhar ou aceita velhas ou usadas interpretaçбes daquilo que é visto. Um "encarar" é um olhar contemplativo às coisas tais como elas são, como se estivessem sendo vistas 
pela primeira vez. É um olhar que rejeita interpretaçðes de segunda-mão sobre as coisas que estão sendo olhadas, é um olhar que exige um esforço do observador, em outras palavras, é um olhar criativo.

Os trabalhos de Charles Burchficld, por exemplo, apresentam à nossa imaginação uma nova visão da nat tireza. Olhando suas pinturas e aquarelas, nós podemos sentir empatia com a sua maneira de desfrutar as cores, sons e sensaçðes da natureza, e perceber o que o artista estava experimentando, ao expressar, numa mesma forma visual, estática, as transformaçðes pelas quais o objeto observado passou, ao receber inferências perceptivas advindas dos outros sentidos.

Acredito que uma obra de arte nasce de uma tal maneira de ver, intensa e criativa. Ela é o símbolo de uma visão criativa, e incorpora não só as idéias, mas também os sentimentos e as sensuais emoçces do artista que a produz. O que é no entanto importante notar,é que a qualidade estética de uma obra de arte reside não em idéias, sentimentos ou emoções consideradas isoladamente, mas sim em suas conéxões com a materialidade do trabalho de arte que é dado à apreciação cie nossos sentidos e imaginação.

O que é válido para o artista é também válido para o observador de uma obra de arte: de modo a ser possível ver criativamente, nós devemos estar conscientes de que a nossa mente tem tendência a fazer imediatas associações com referências visuais passadas e somente quando nós evitamos os efeitos cegantes do hábito, da rotina, da familiaridade e do preconceito, nós podemos começar a olhar as coisas com novos olhos e talvez apreender o mundo à nossa volta com maior intensidade.

Acredito que existem obras de arte que estimulam esta capacidade de visão criativa no observador mais do que outras. Em minha opinião, são aquelas que possuem, de alguma maneira, aquelas mágicas propriedades do silêncio, que exigem do observador seja um olhar lento, ou atento, ou meditativo, ou de outro modo, que "sacodem" a mecanização de nossa visão,estimulando- nos com uma série de novos "insights".

O silêncio nas artes visuais é uma chamada para uma nova visão, uma suspensão de significados "traduzíveis", uma questão em aberto. 


\section{BI'BLIOGRAFIA}

BARTHES. Roland Empire of stgns. Trans. by Richard Howard. New York, Hill and Wang, 1970.

Image, music, text Trans by Stephen Heath. New York, Hill and Wang, 1977.

CASSIRER, Ernst. An essay on man. New Haven, Yale University Press, 1974.

-... Language and myth. Trans. by Susanne K. Langer. New York, Dover, 1953.

DEWEY, John. Art as experience. New York, Putnam, 1979.

LANGER, Susanne K. Feeling and form. New York, Charles Scribners, 1953.

-- Philosophy in a new key. 3.ed. Cambridge, Harvard University Press, 1980.

-... Introduction to symbollic logic. New York, Dover. 1953.

-.. Philosophical sketches. Baltimore, Join Hopkins, 1962.

MILLER, Georg A. Psychology, the science of mental life. New York, Harper \& Row, 1962.

PENNEY, Charles Rand et alli. Charles Burchfield. Catalogue of the Charles Penney Collection. Rochester, Memorial Art Gallery; s.l.. Smithsonian Institution Traveling Exhibition Service, 1978.

SANDLER, Irving. The triumph of American painting. New York, Harper \& Row, 1970.

NILZA GRAU HAERTEL Mestre em Gravura pela Colorado State University, USA; Prof. Adjunto de Gravura do Departamento de Artes Visuais do Instituio de Artes da UFRGS. 


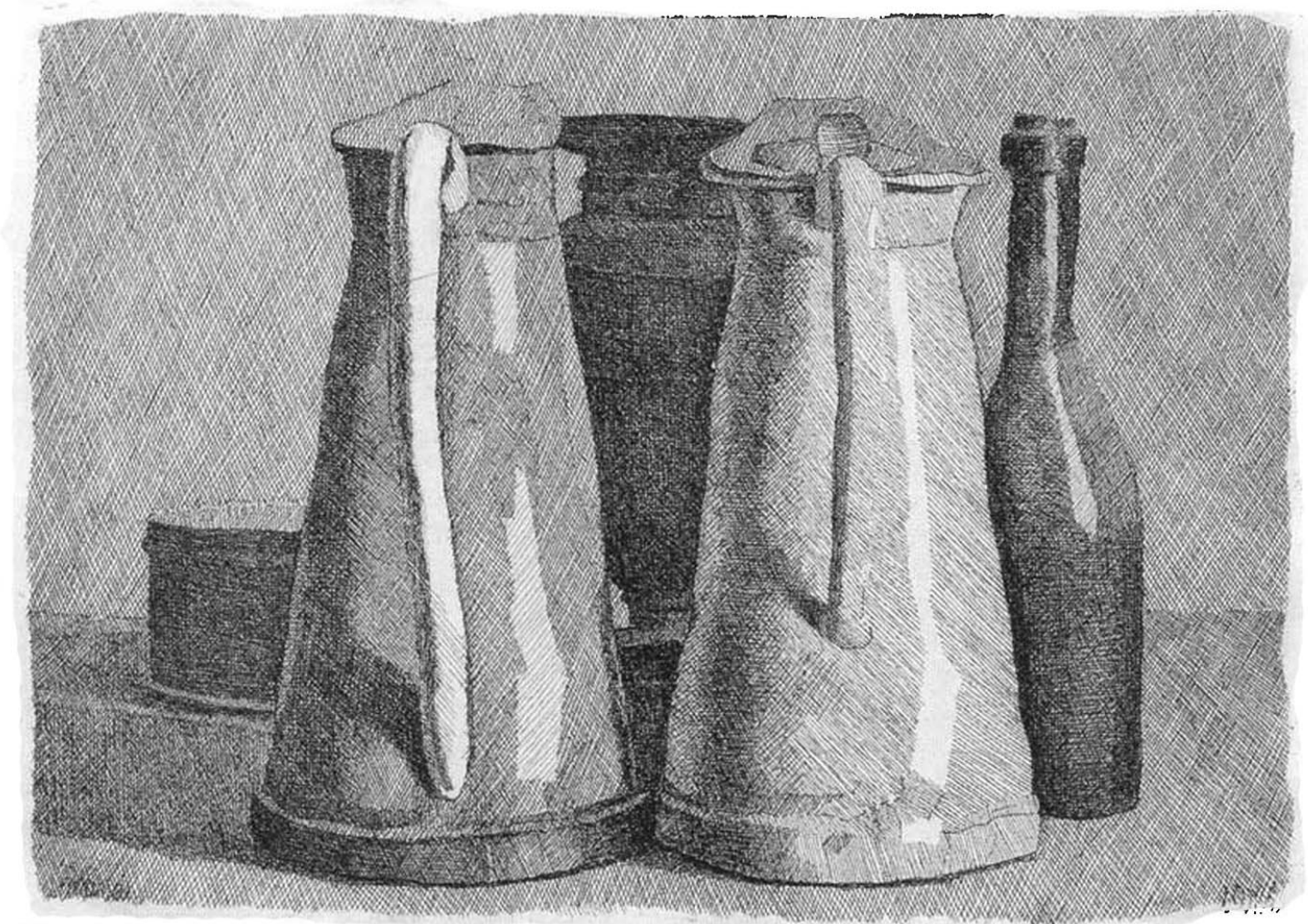

Giorgio Morandi. "Garrafas e Jarras". c. 1940. água-forte Col. particular de Mr. e Mrs. Thomas Burnside, USA

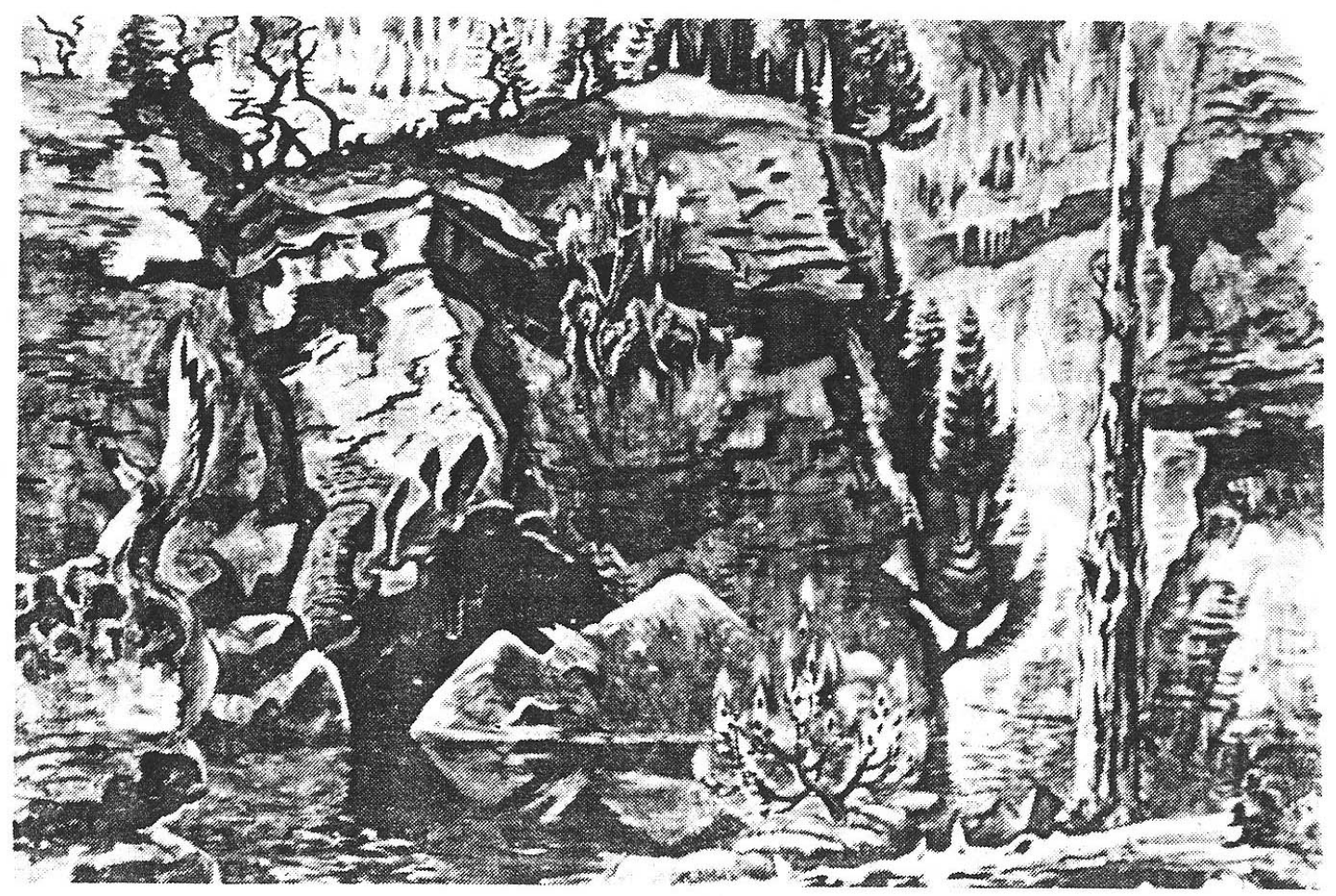

Charles Burchfield. "Solidão". 1931. aquarela e carvão Memorial Art Gallery, Rochester, USA

60 


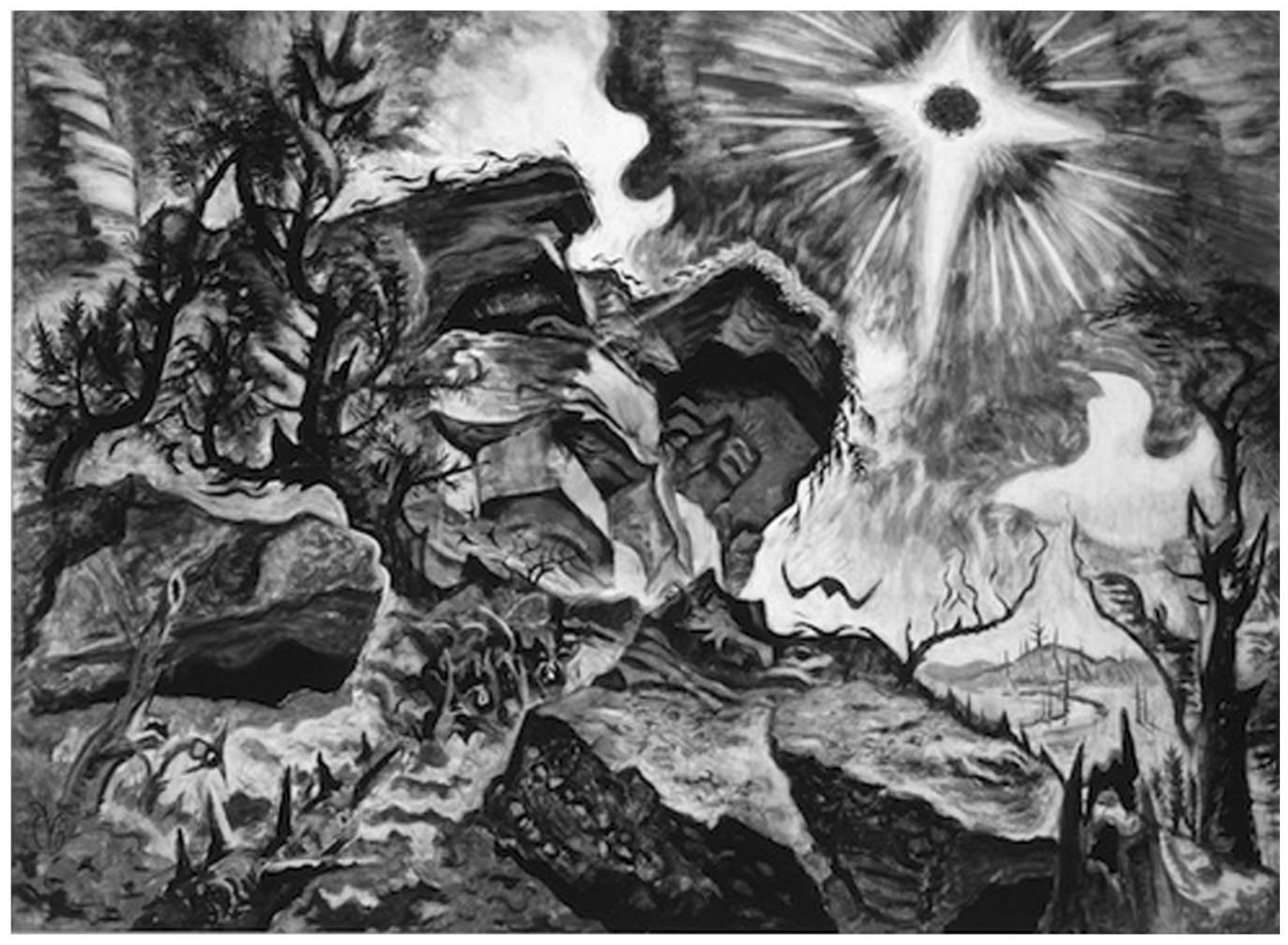

Charles Burchfield. "Sol e Rochedos". c. 1944. desenho Memorial Art Gallery, Rochester, USA 